\title{
Synthesis and properties of ladder type BN-heteroacenes and diazabenzoindoles built on pyrrolopyrrole scaffold
}

\section{Supporting Information}

\author{
Mariusz Tasior and Daniel T. Gryko*
}

Table of Contents

S2. $\quad{ }^{1} \mathrm{H},{ }^{13} \mathrm{C},{ }^{10} \mathrm{~B}$ NMR Spectra

S22 Crystallographic data for 6.

S24 Mass spectra

S24 Photographic images of powdered samples of compounds 5-8. 


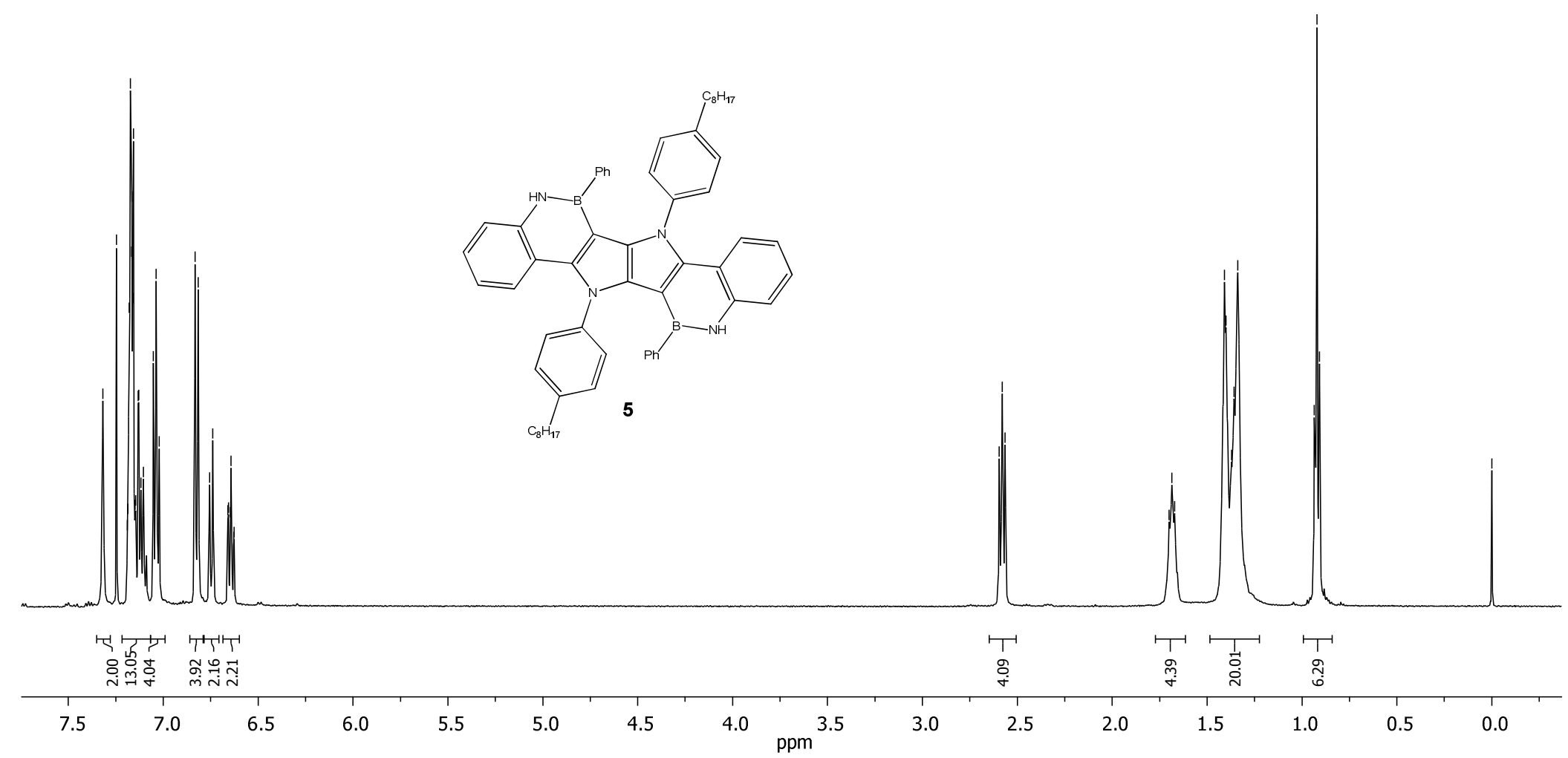


象然战

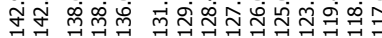

४रा रोiा
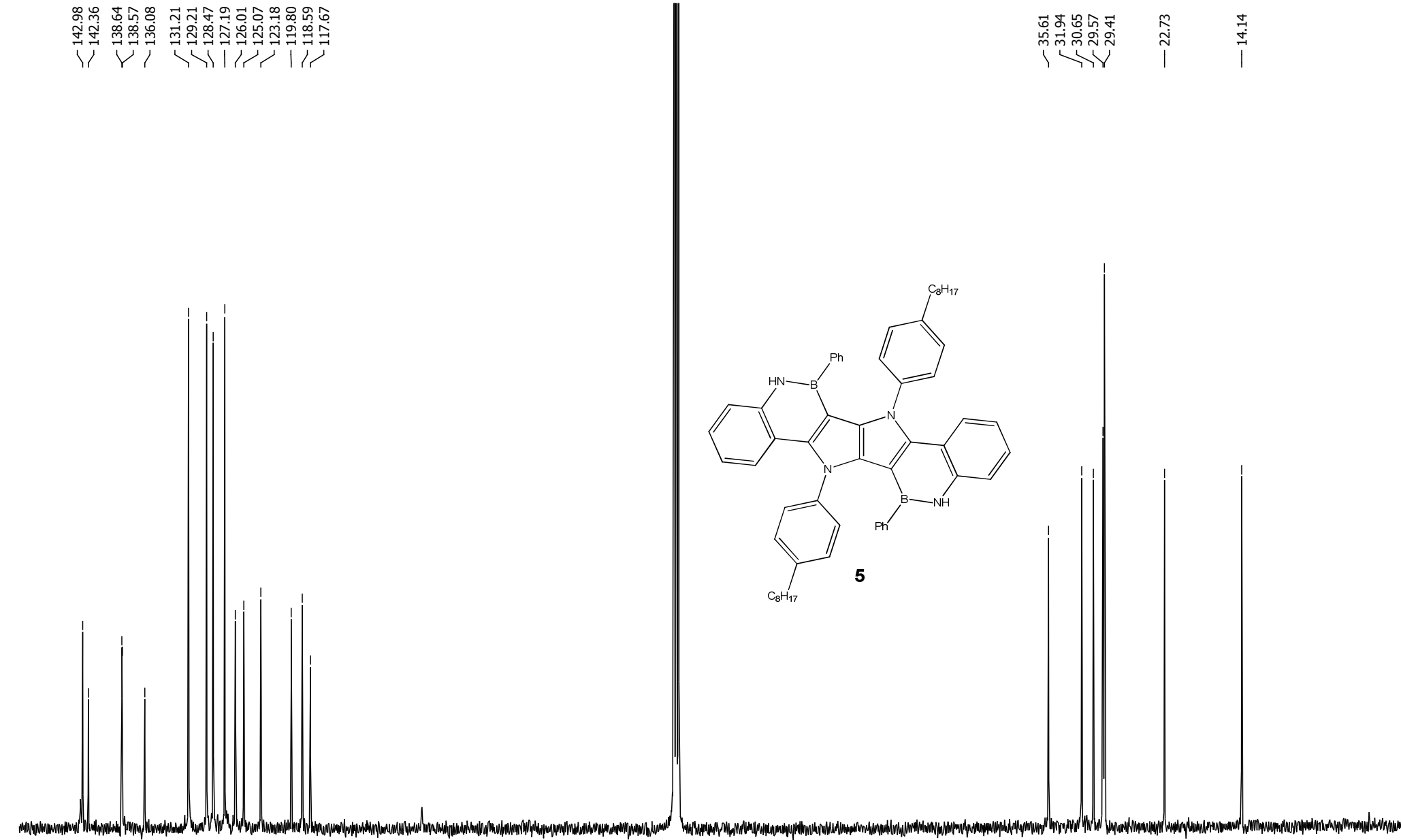

150

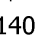

130

120

110

100

90

80

${ }^{70}$

60

50

40

30

20

10 0 


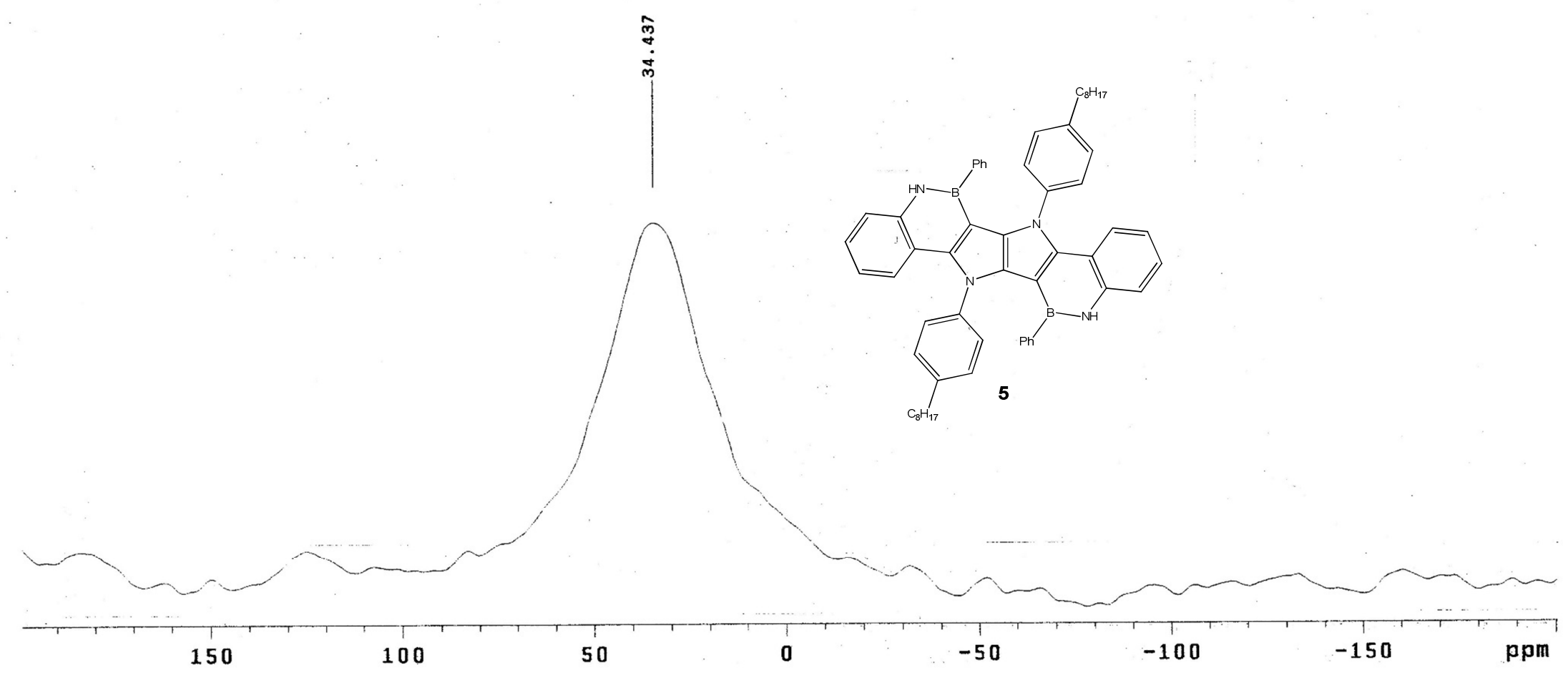




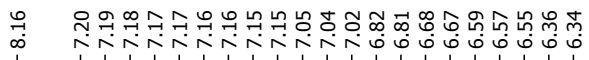

ل攺

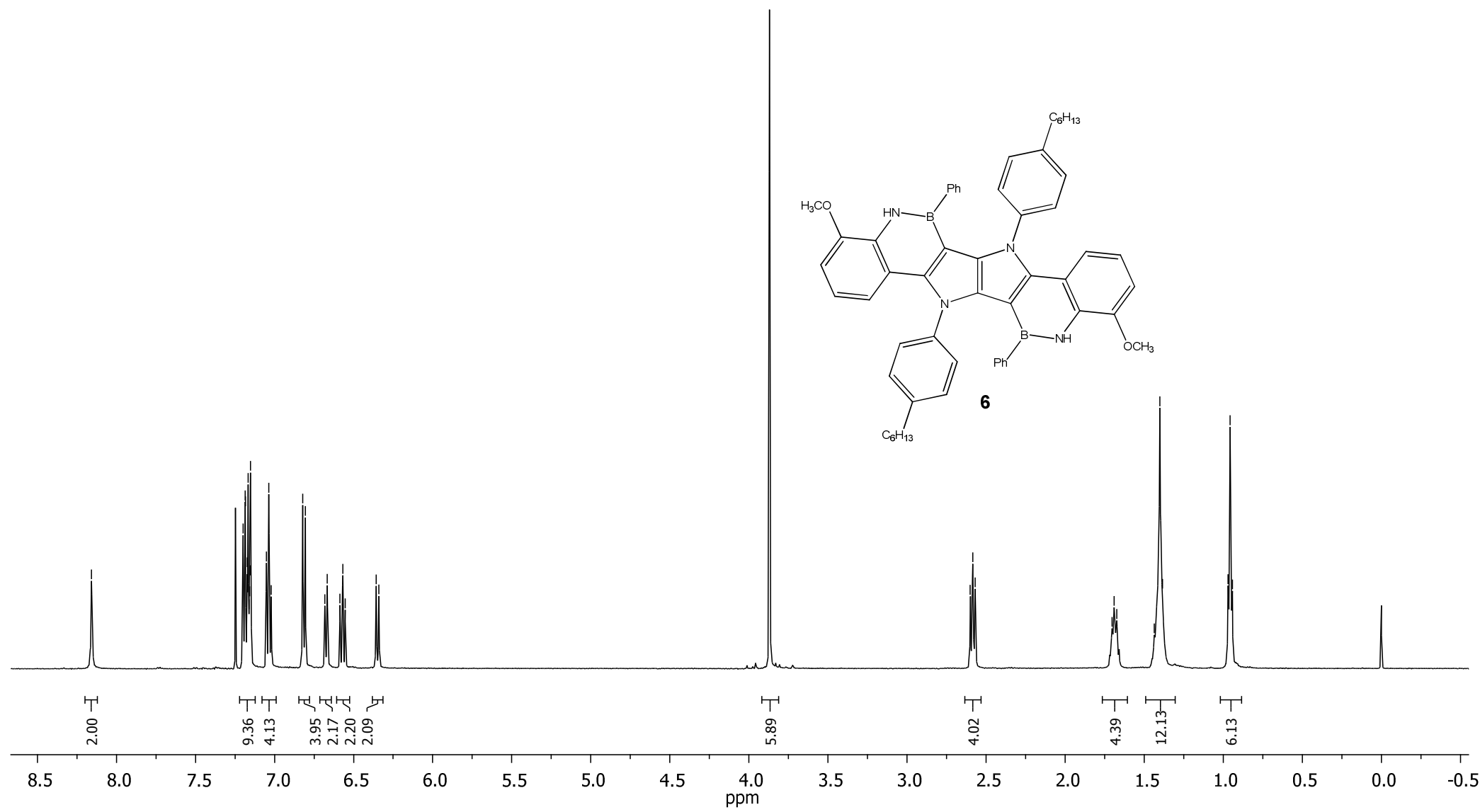



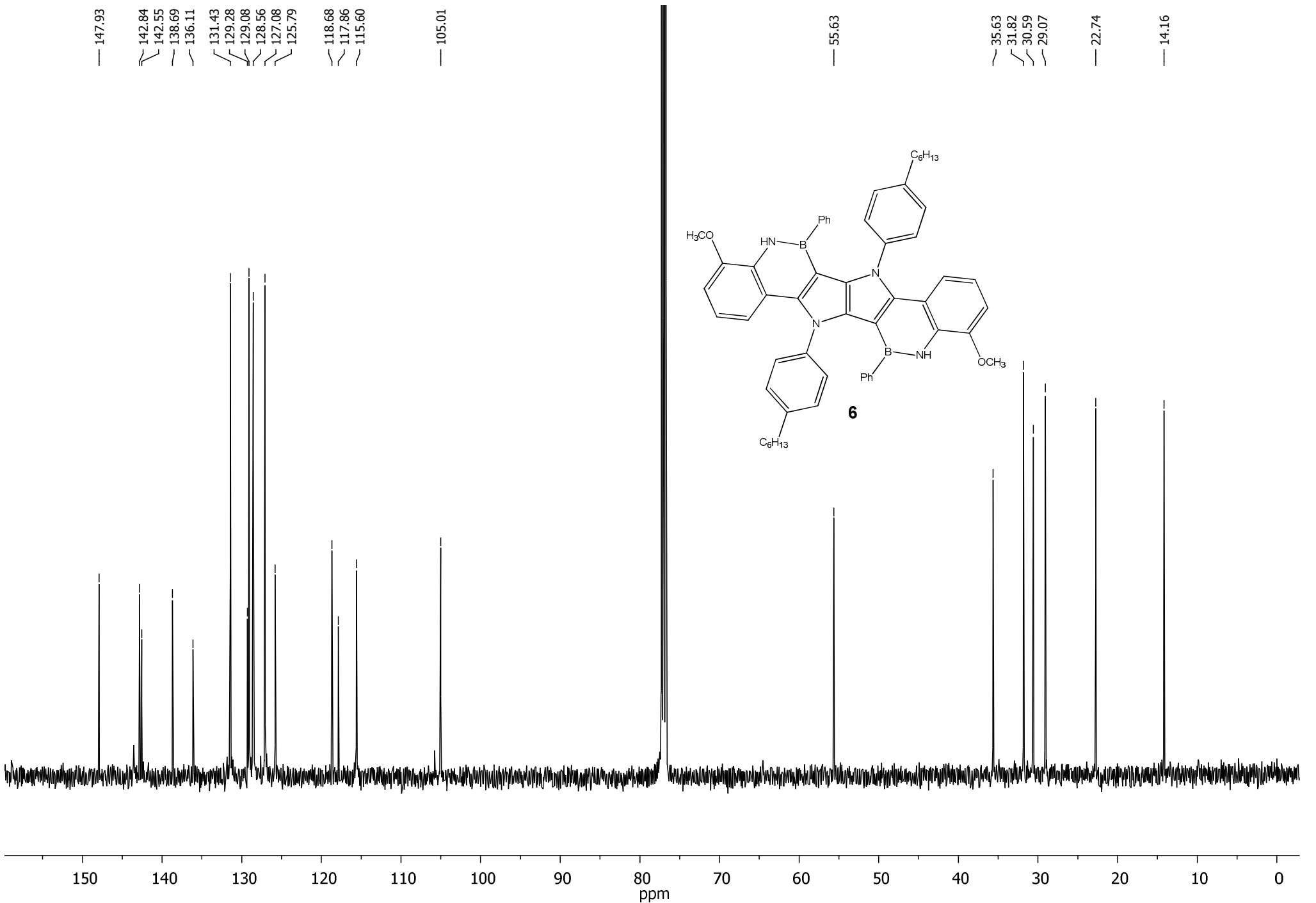


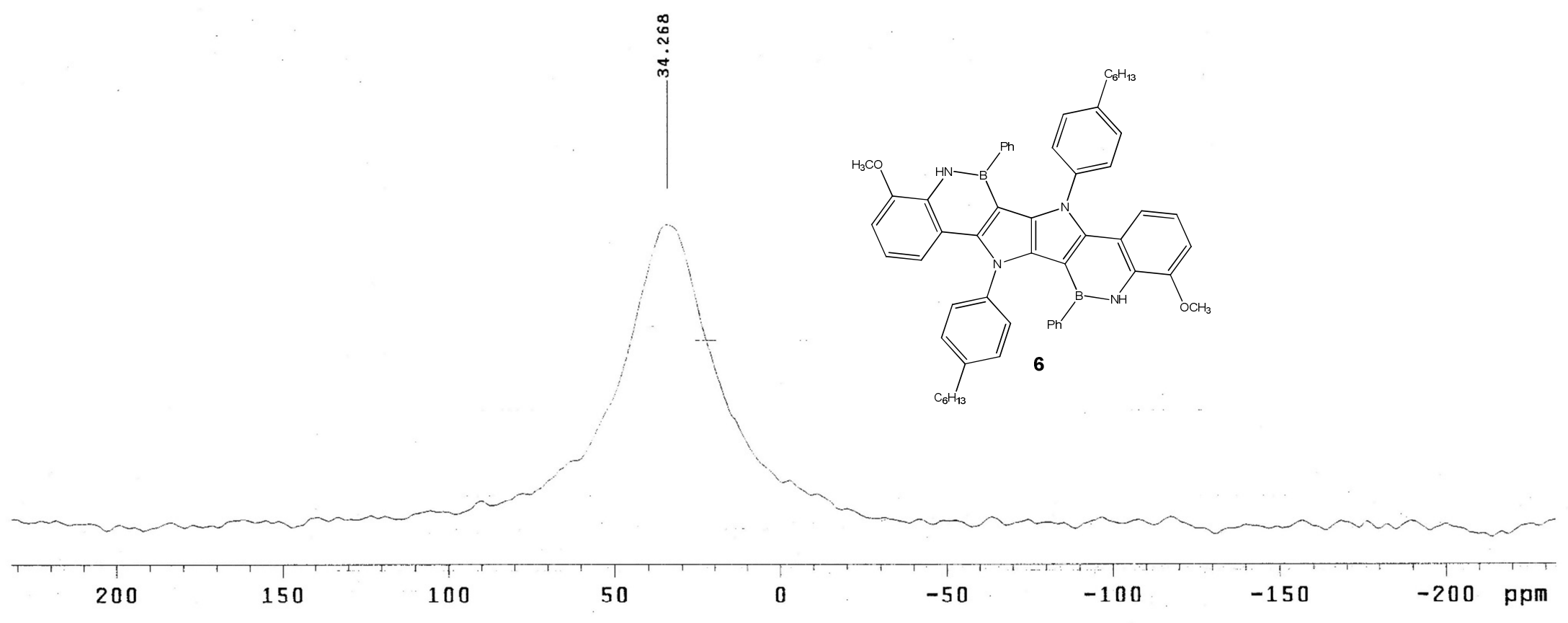



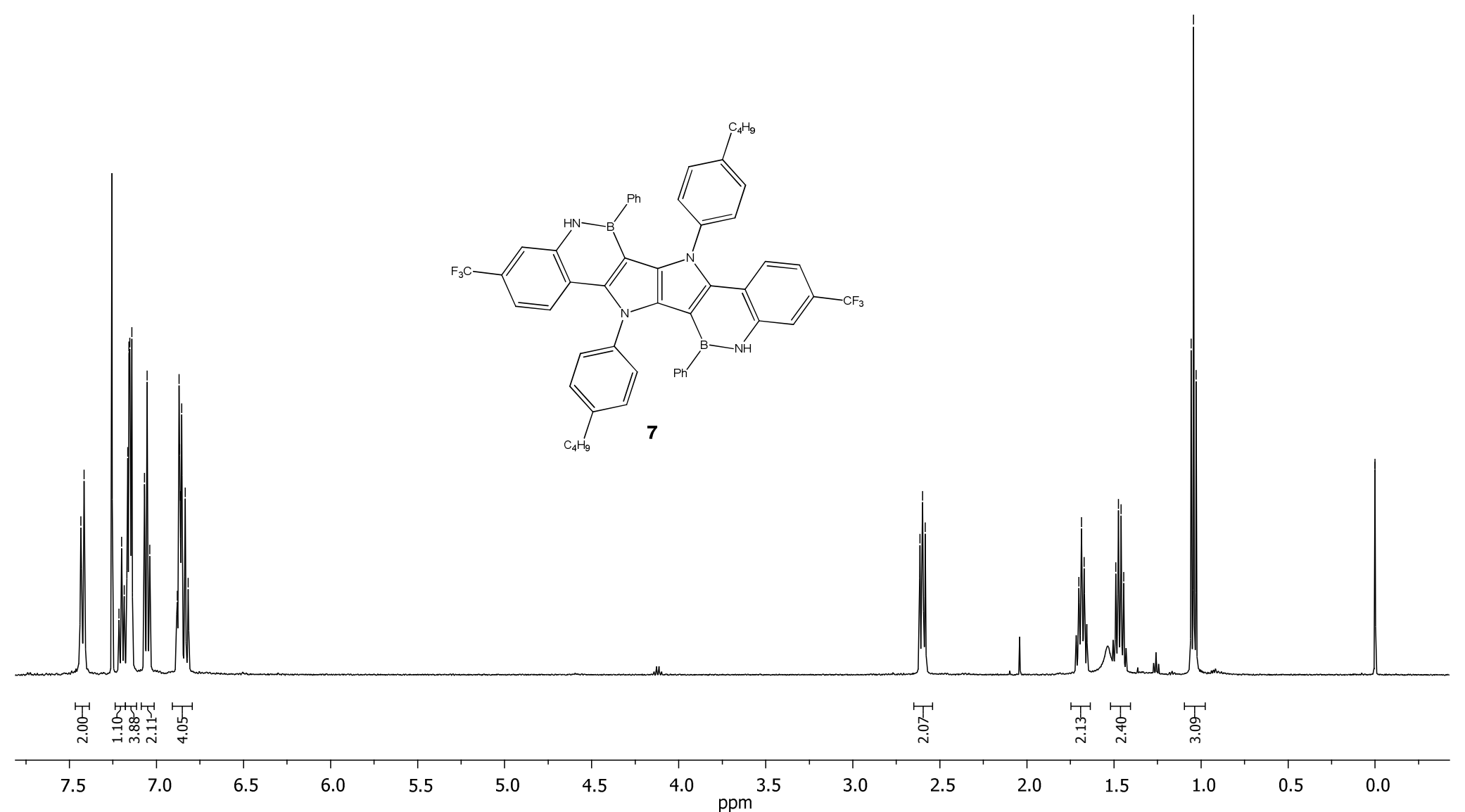


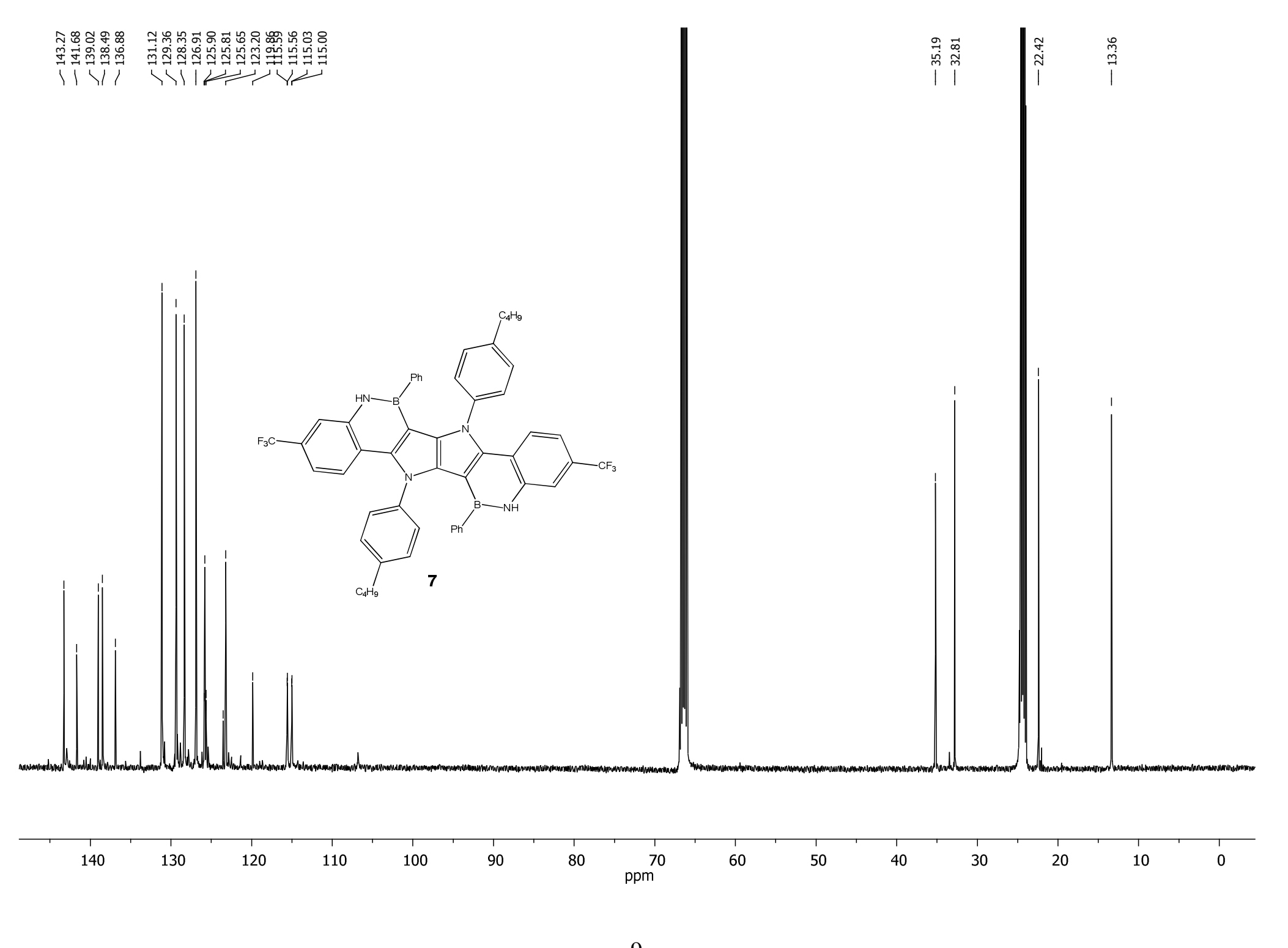




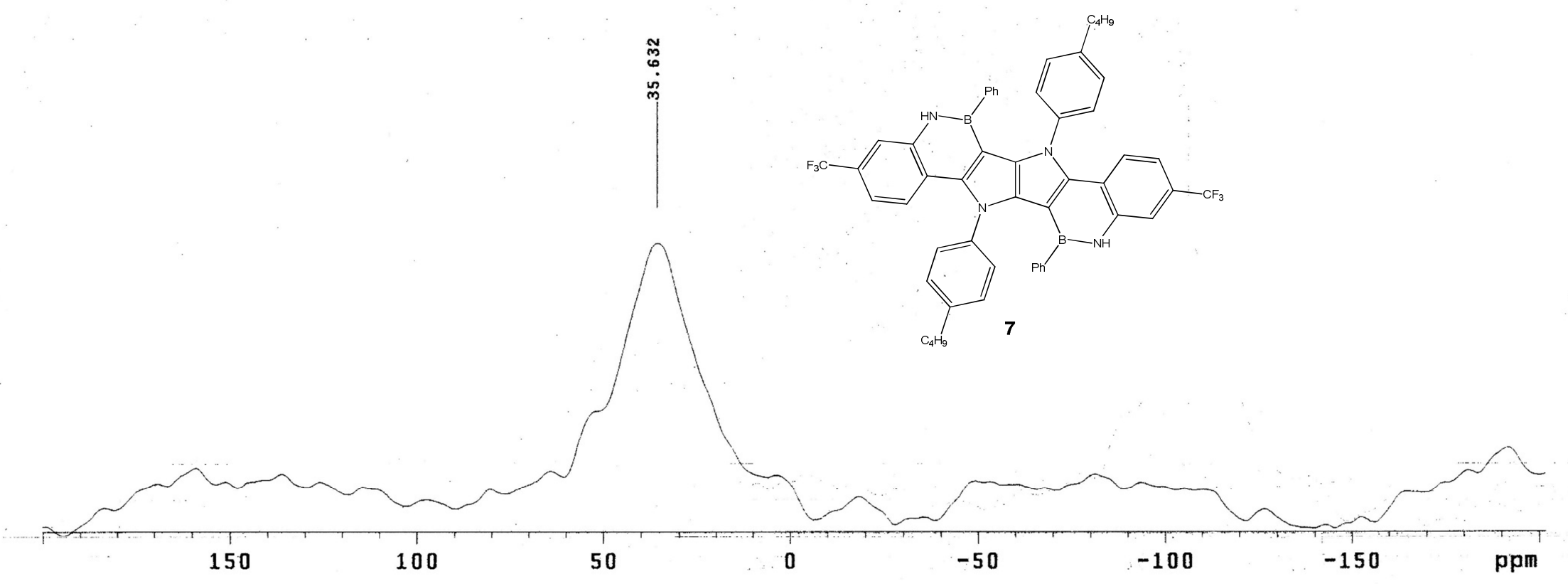



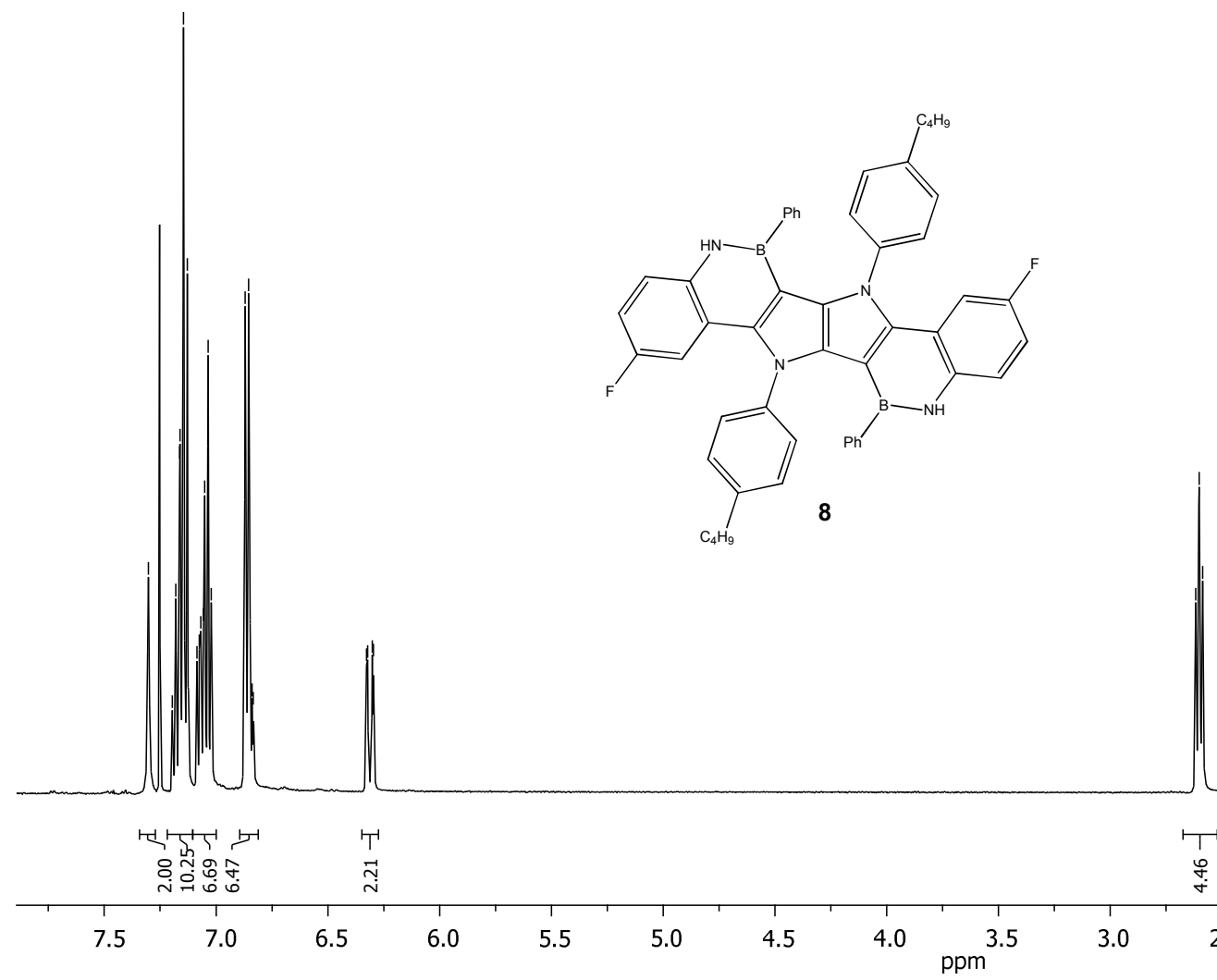

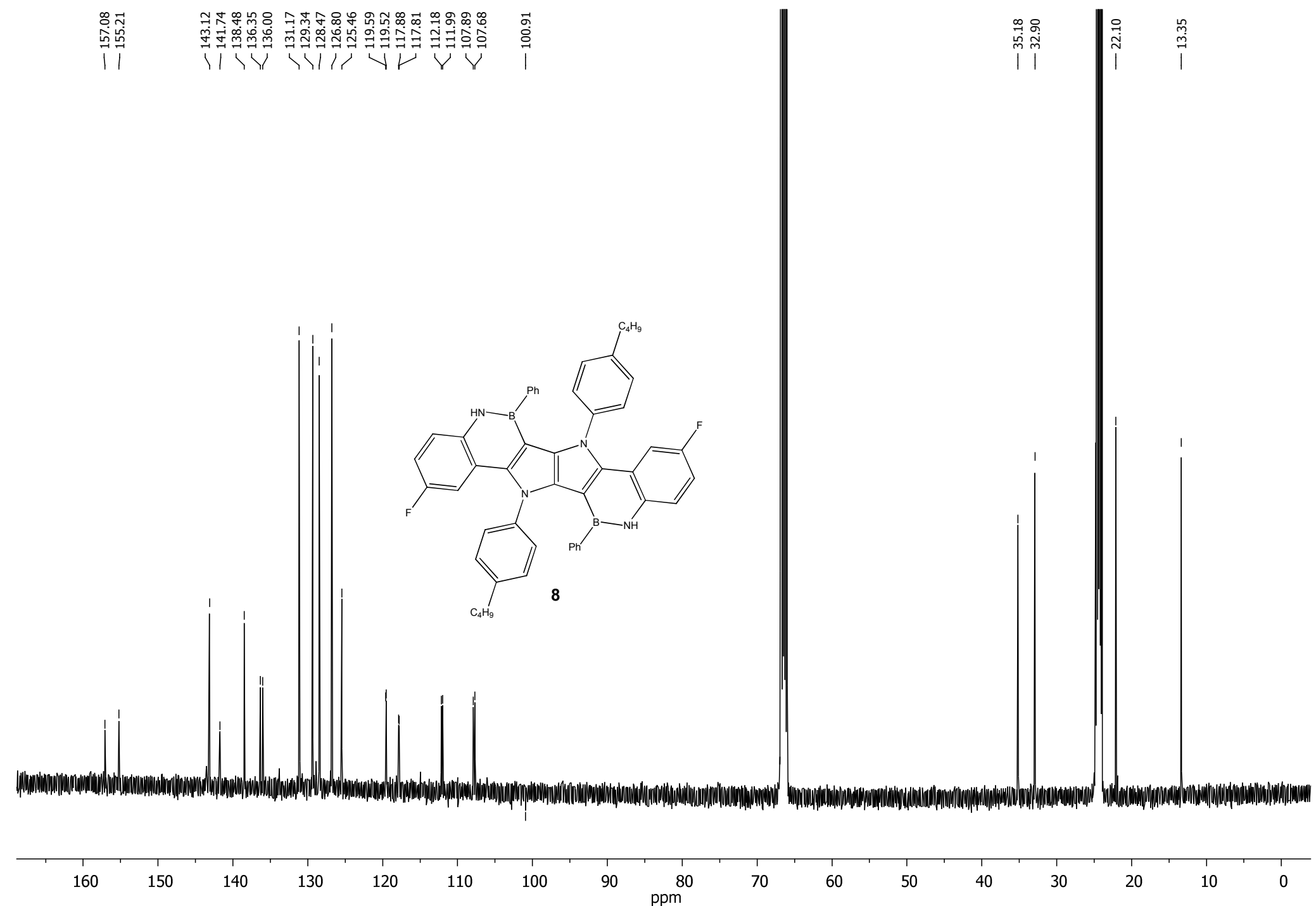


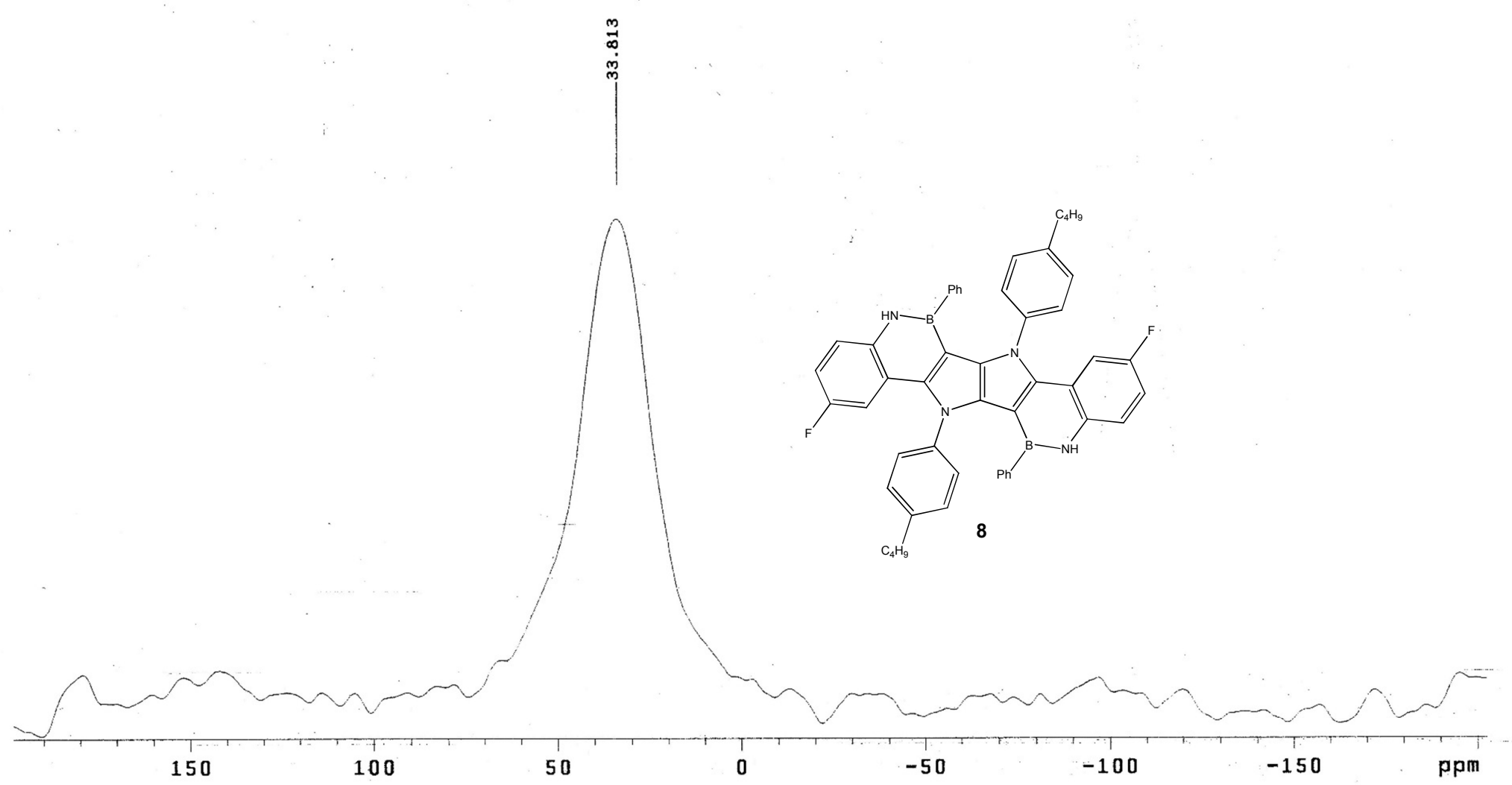




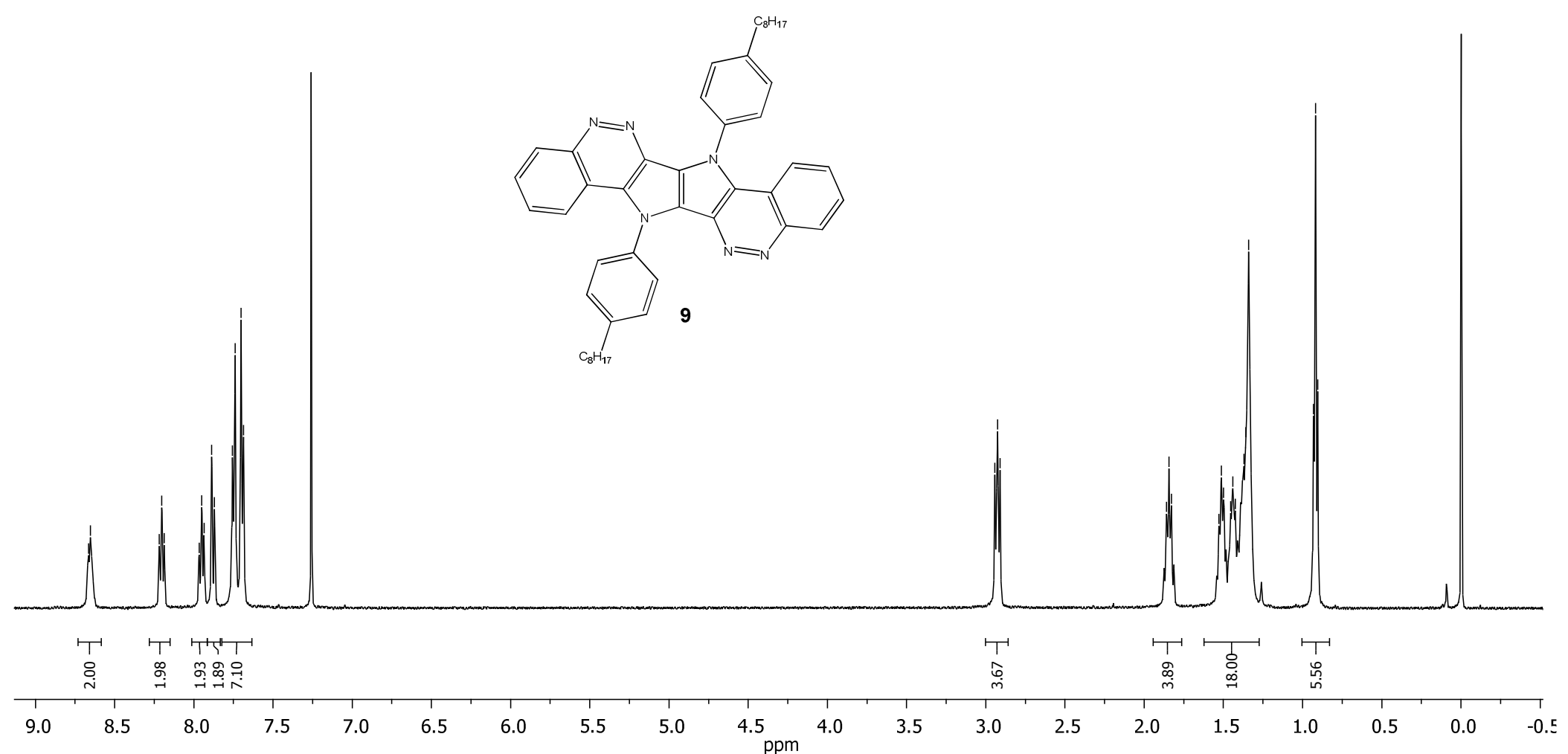



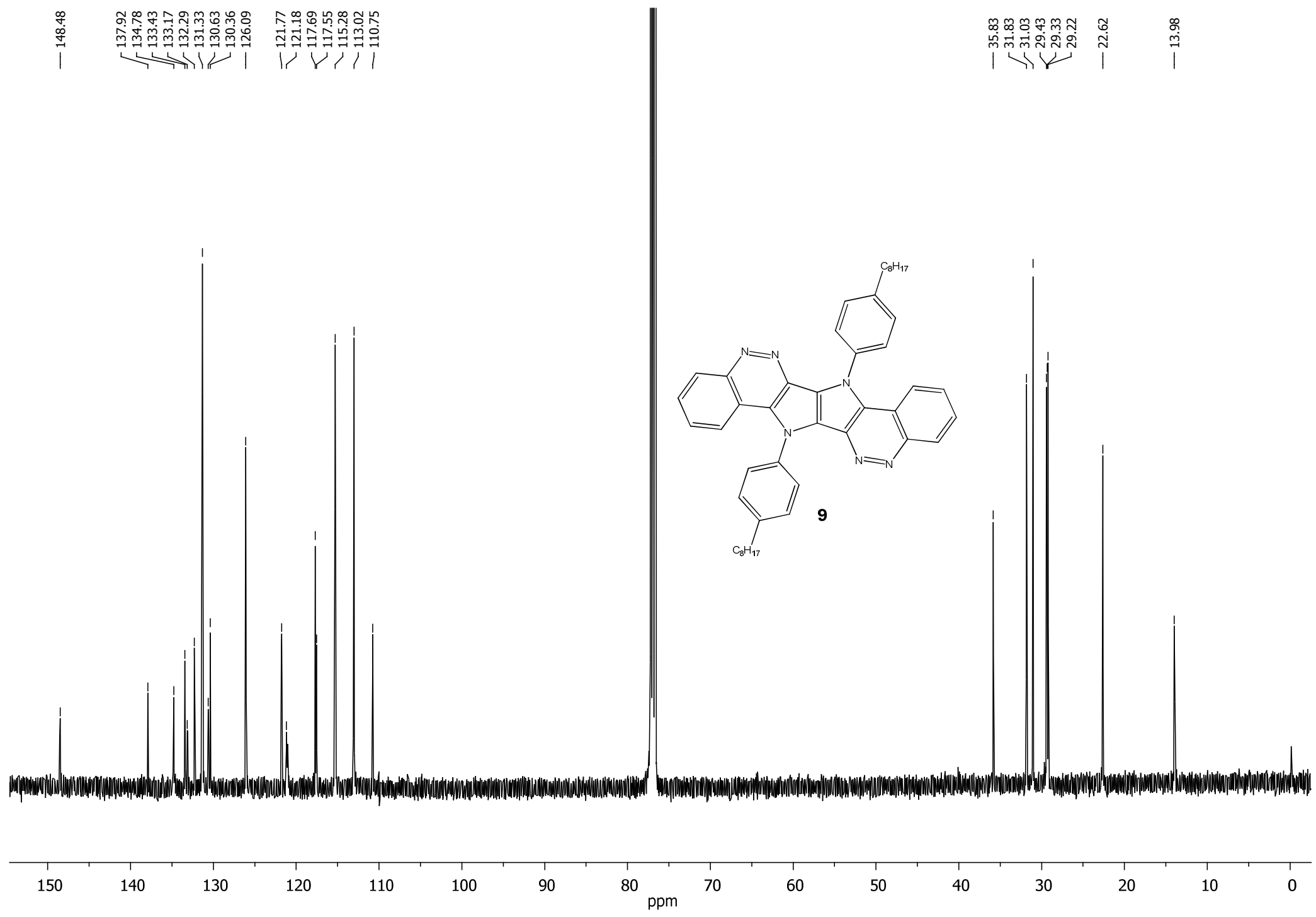

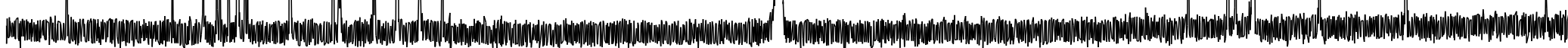




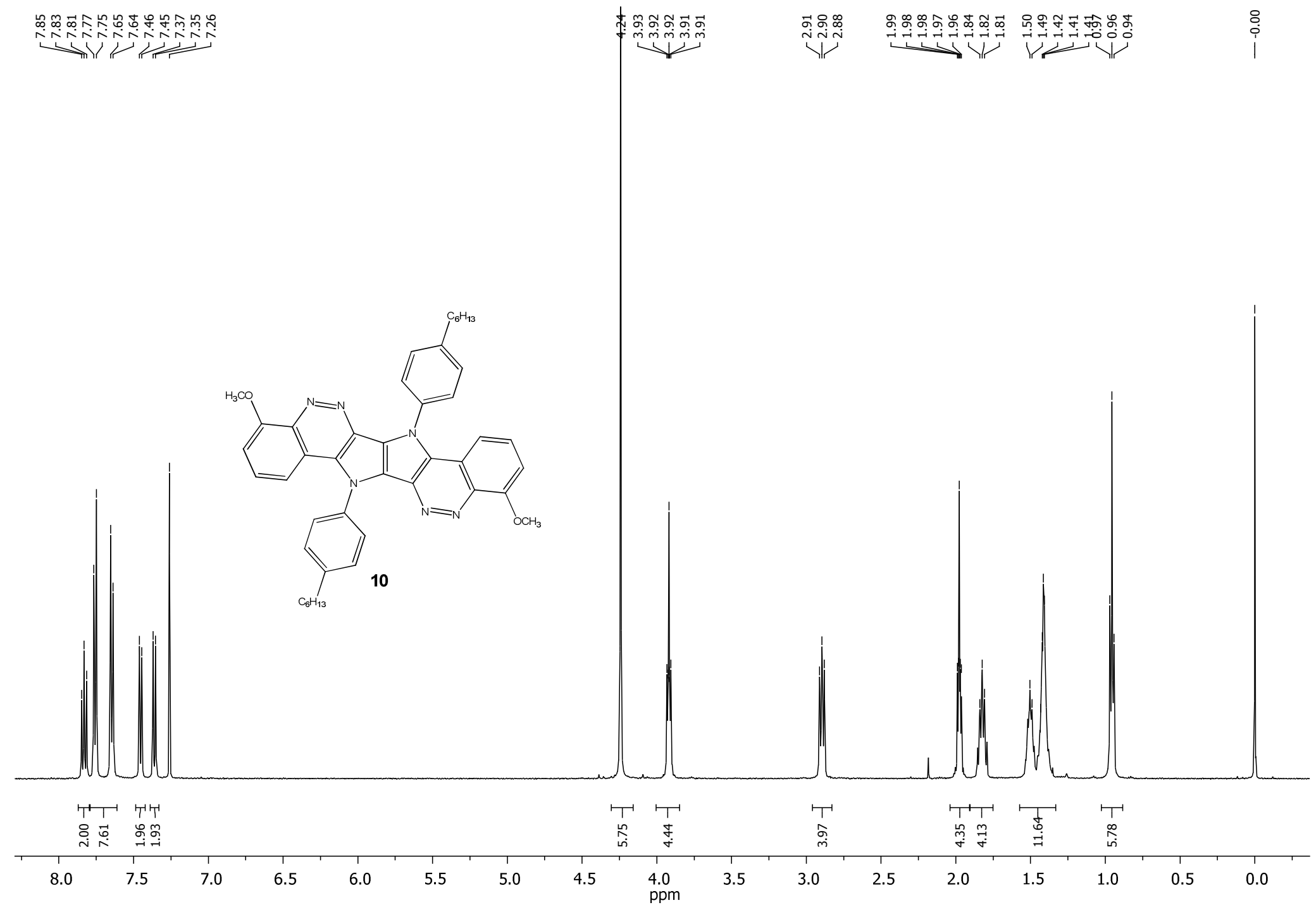




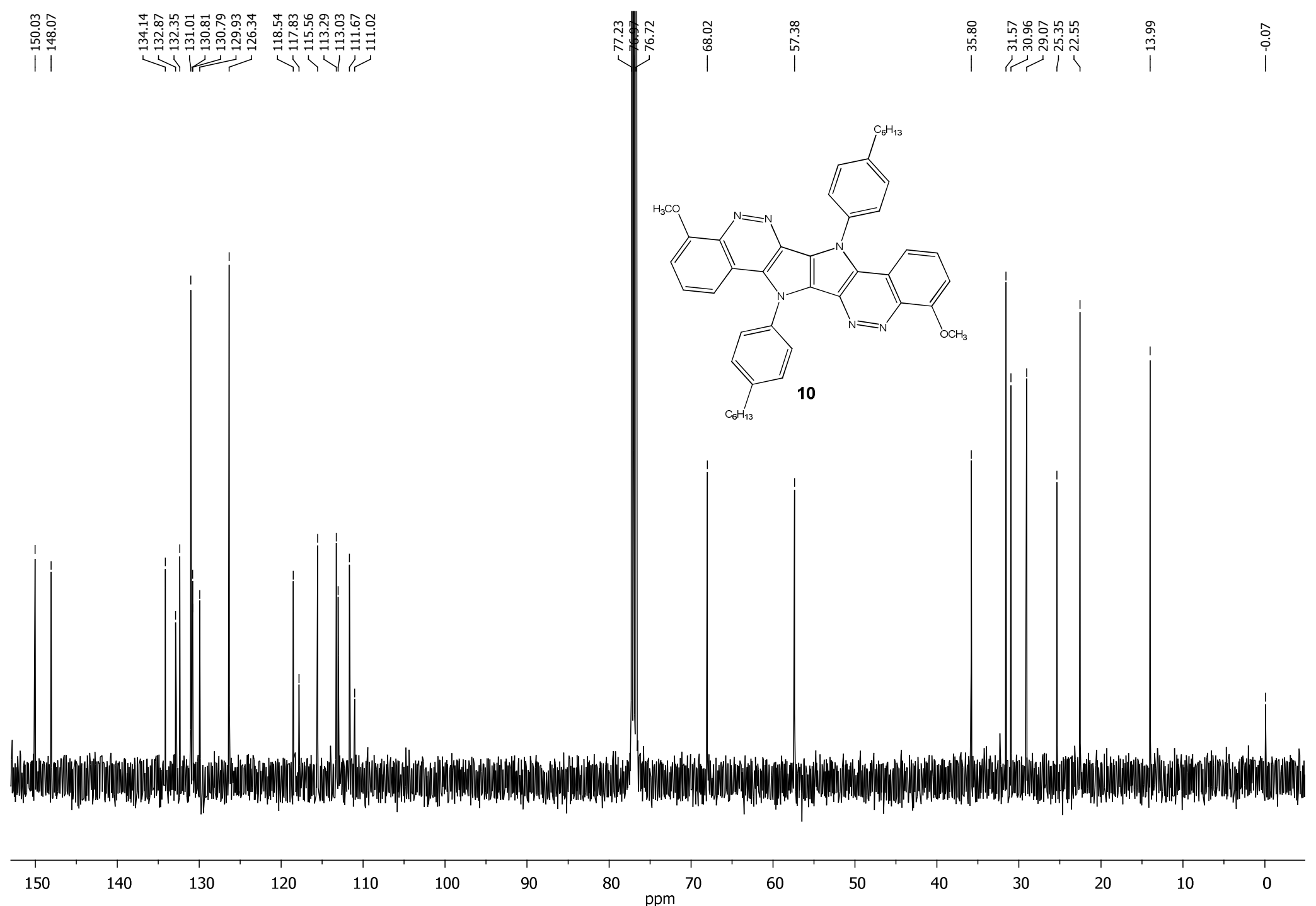




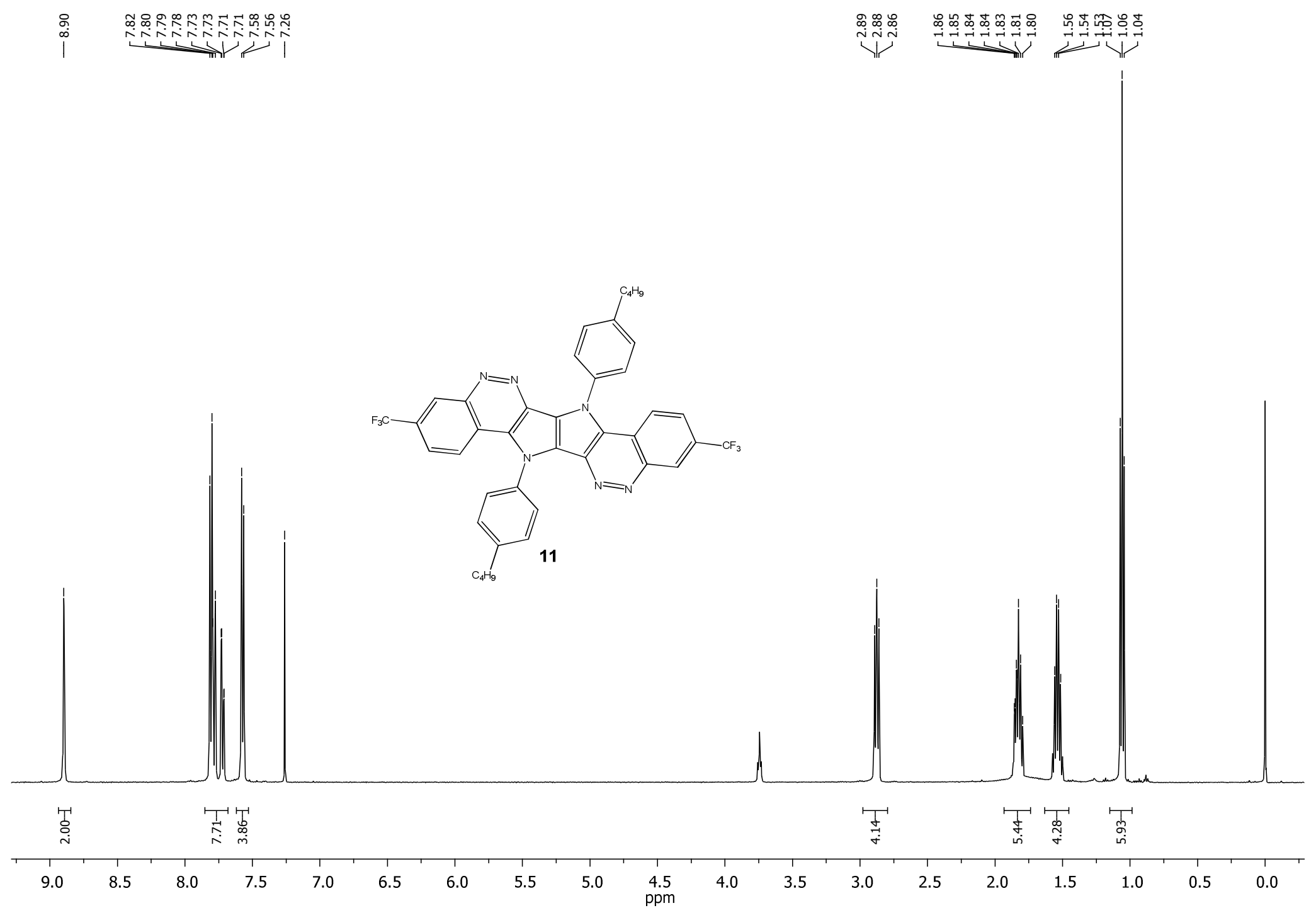




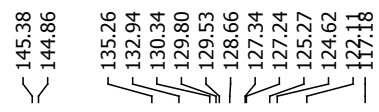

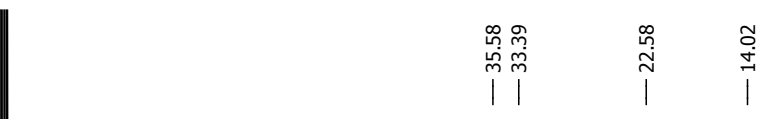
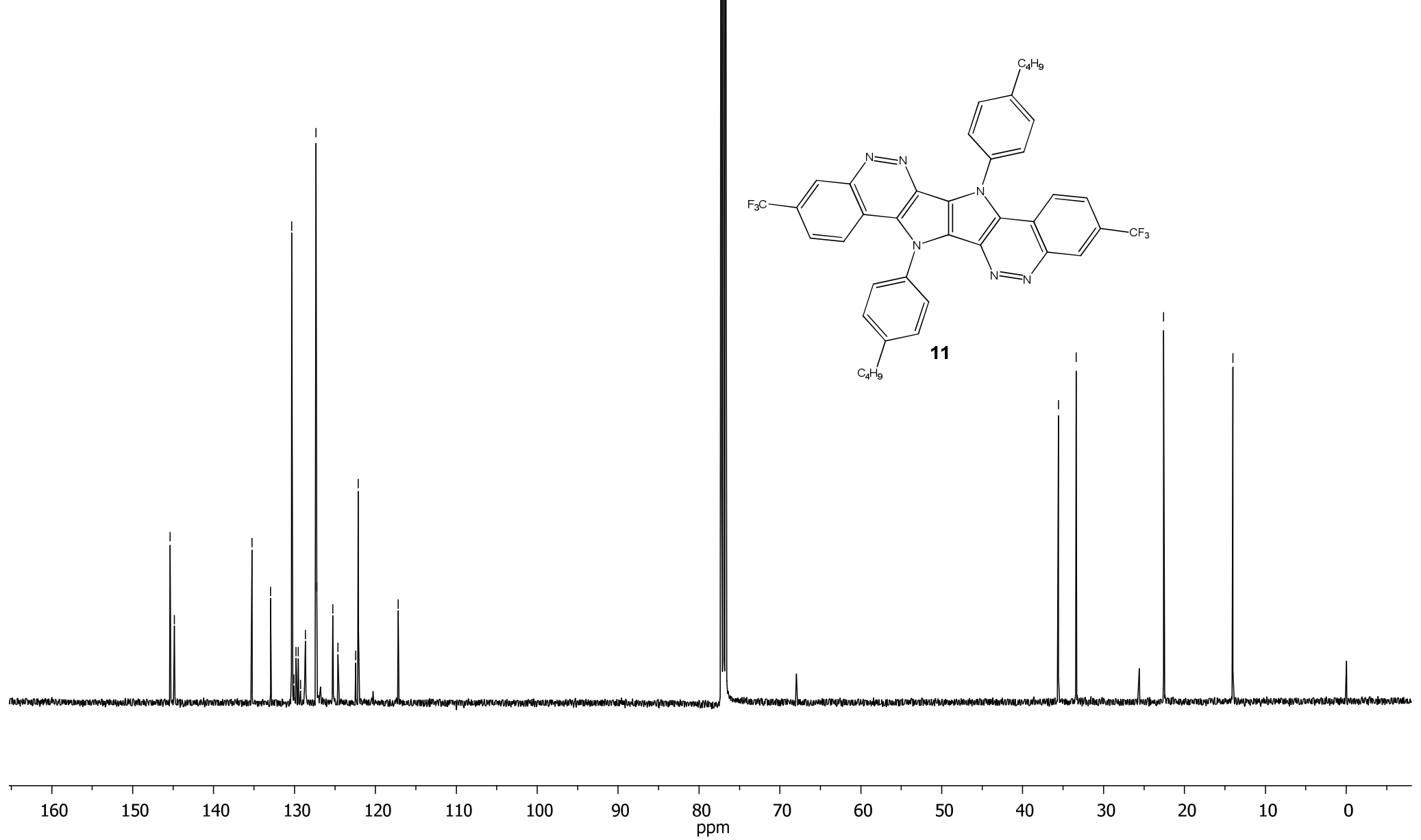


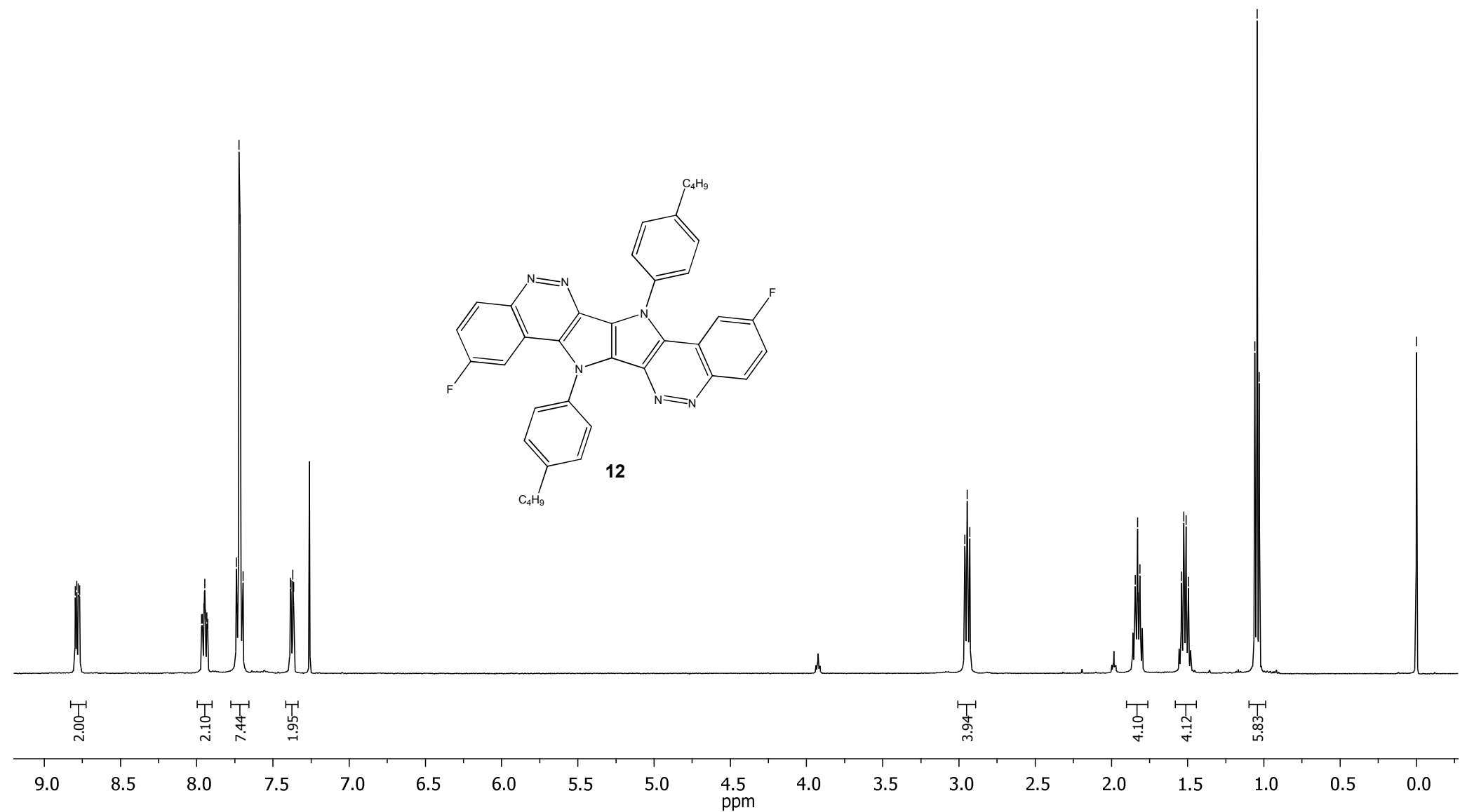



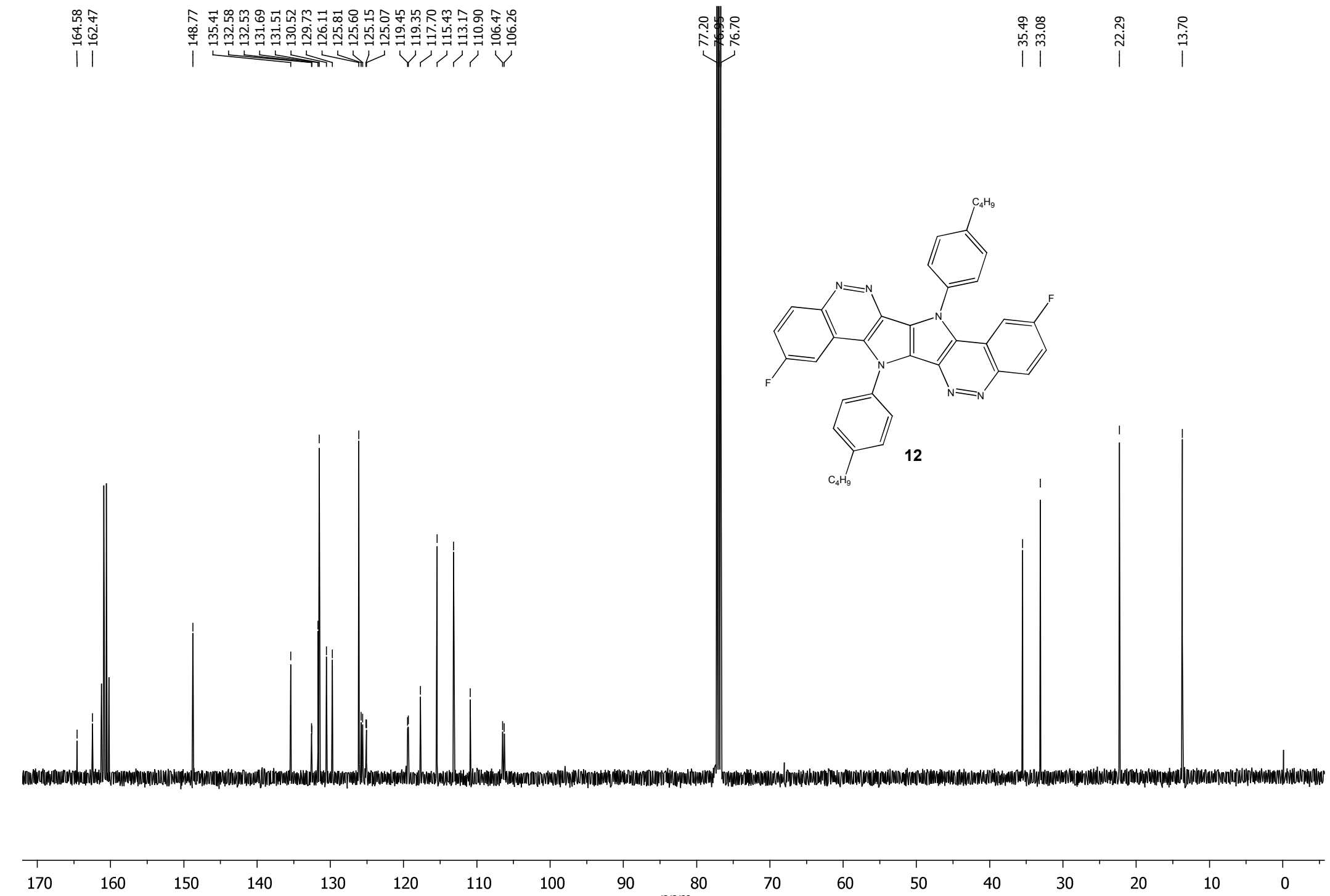

150
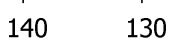

120

110

100

90

$\mathrm{ppm}^{80}$

$70 \quad 60$

50 


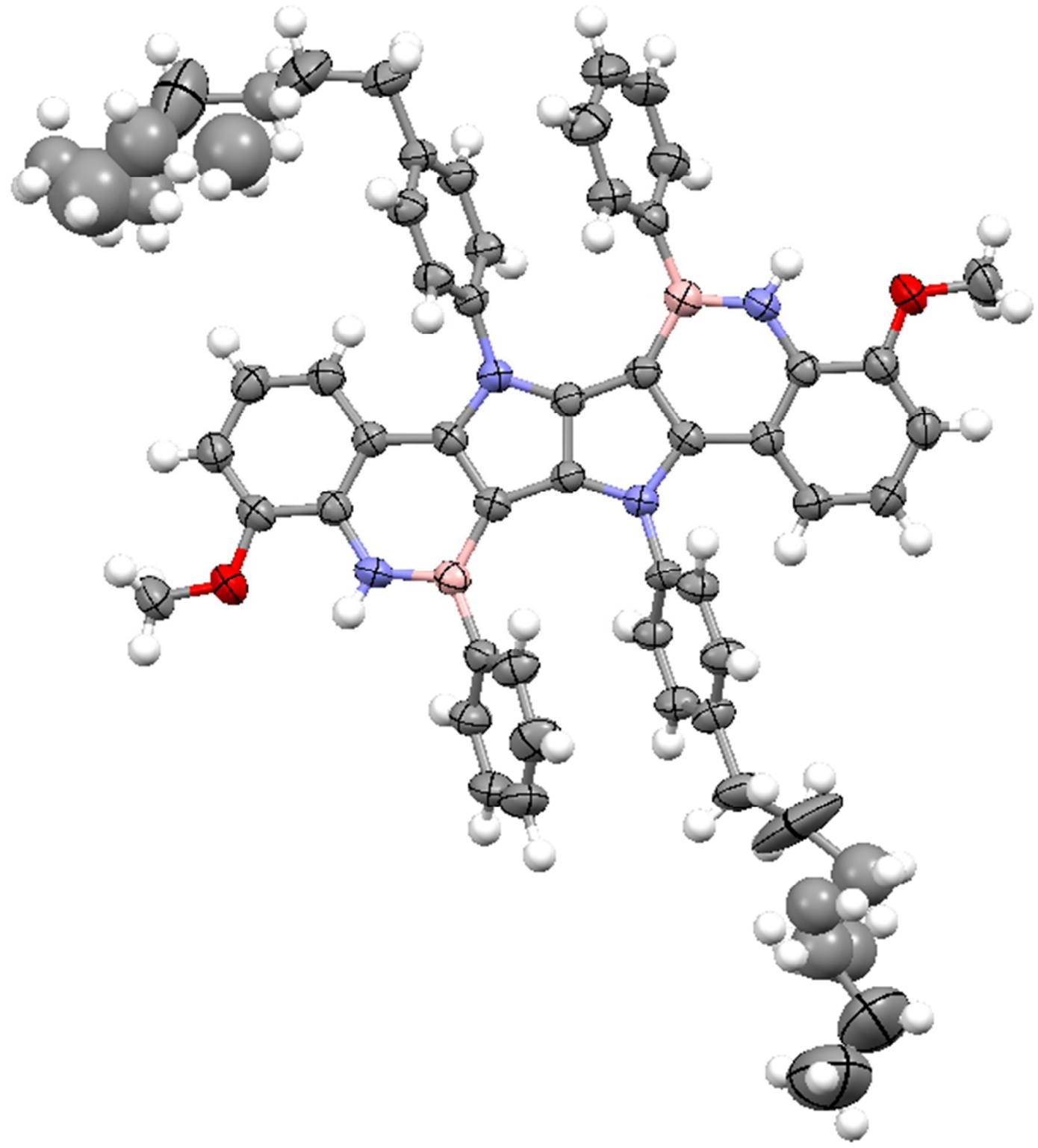

Figure S1. The X-ray structure of $\mathbf{6}$. Hydrogens are drawn as fixed-size spheres of radius 0.3 $\AA$, thermal ellipsoids are shown at the $50 \%$ probability level. 
Table S1. Crystallographic data for 6. CCDC No. 1474772

\begin{tabular}{|c|c|c|}
\hline Chemical formula & \multicolumn{2}{|l|}{$\mathrm{C}_{56} \mathrm{H}_{58} \mathrm{~B}_{2} \mathrm{~N}_{4} \mathrm{O}_{2}$} \\
\hline Formula weight & \multicolumn{2}{|l|}{$840.68 \mathrm{~g} / \mathrm{mol}$} \\
\hline Temperature & \multicolumn{2}{|l|}{$296(2) \mathrm{K}$} \\
\hline Wavelength & \multicolumn{2}{|l|}{$1.54178 \AA$} \\
\hline Crystal size & \multicolumn{2}{|c|}{$0.131 \times 0.184 \times 0.302 \mathrm{~mm}$} \\
\hline Crystal habit & \multicolumn{2}{|c|}{ colorless needle } \\
\hline Crystal system & \multicolumn{2}{|l|}{ triclinic } \\
\hline Space group & \multicolumn{2}{|l|}{$\mathrm{P}-1$} \\
\hline \multirow[t]{3}{*}{ Unit cell dimensions } & $\mathrm{a}=14.0381(11) \AA$ & $\alpha=80.151(5)^{\circ}$ \\
\hline & $\mathrm{b}=14.1845(11) \AA$ & $\beta=62.153(5)^{\circ}$ \\
\hline & $\mathrm{c}=14.8760(12) \AA$ & $\gamma=63.603(4)^{\circ}$ \\
\hline Volume & $2343.5(3) \AA^{3}$ & \\
\hline $\mathbf{Z}$ & \multicolumn{2}{|l|}{2} \\
\hline Diffractometer & \multicolumn{2}{|c|}{ Bruker APEX-II CCD } \\
\hline Radiation source & \multicolumn{2}{|c|}{ fine-focus sealed tube, $\mathrm{CuK}_{\alpha}$} \\
\hline Reflections collected & \multicolumn{2}{|c|}{53562} \\
\hline Independent reflections & \multicolumn{2}{|c|}{$7810[\mathrm{R}($ int $)=0.0655]$} \\
\hline Tmin, Tmax & \multicolumn{2}{|c|}{$0.851,0.931$} \\
\hline Absorption correction & \multicolumn{2}{|l|}{ numerical } \\
\hline Refinement method & \multicolumn{2}{|c|}{ Full-matrix least-squares on $\mathrm{F}^{2}$} \\
\hline Function minimized & \multicolumn{2}{|l|}{$\sum \mathrm{w}\left(\mathrm{F}_{\mathrm{o}}^{2}-\mathrm{F}_{\mathrm{c}}^{2}\right)^{2}$} \\
\hline Data / restraints / parameters & \multicolumn{2}{|l|}{$7810 / 9 / 623$} \\
\hline Goodness-of-fit on $\mathbf{F}^{2}$ & \multicolumn{2}{|l|}{1.066} \\
\hline$\Delta / \sigma_{\max }$ & \multicolumn{2}{|l|}{0.056} \\
\hline \multirow[t]{2}{*}{ Final $\mathbf{R}$ indices } & 4336 data; $\mathrm{I}>2 \sigma(\mathrm{I})$ & $\begin{array}{l}\mathrm{R} 1=0.0869, \mathrm{wR} 2= \\
0.2108\end{array}$ \\
\hline & all data & $\begin{array}{l}\mathrm{R} 1=0.1466, \mathrm{wR} 2= \\
0.2295\end{array}$ \\
\hline Largest diff. peak and hole & \multicolumn{2}{|c|}{0.692 and $-0.266 \mathrm{e}^{-3}$} \\
\hline
\end{tabular}

The crystals of $\mathbf{6}$ suitable for X-ray crystallography were obtained by diffusion of hexane into a solution of $\mathbf{6}$ in THF. The X-ray intensity data were measured on a Bruker APEX-II CCD system equipped with a graphite monochromator and a $\mathrm{CuK}_{\alpha}$ fine-focus sealed tube $(\lambda=$ $1.54178 \AA$ ). . A total of 4638 frames were collected. The total exposure time was 64.42 hours. The frames were integrated with the Bruker SAINT software package using a narrow-frame algorithm. Data were corrected for absorption effects using the numerical method (SADABS). The structure was solved and refined using the Bruker SHELXTL Software Package. 


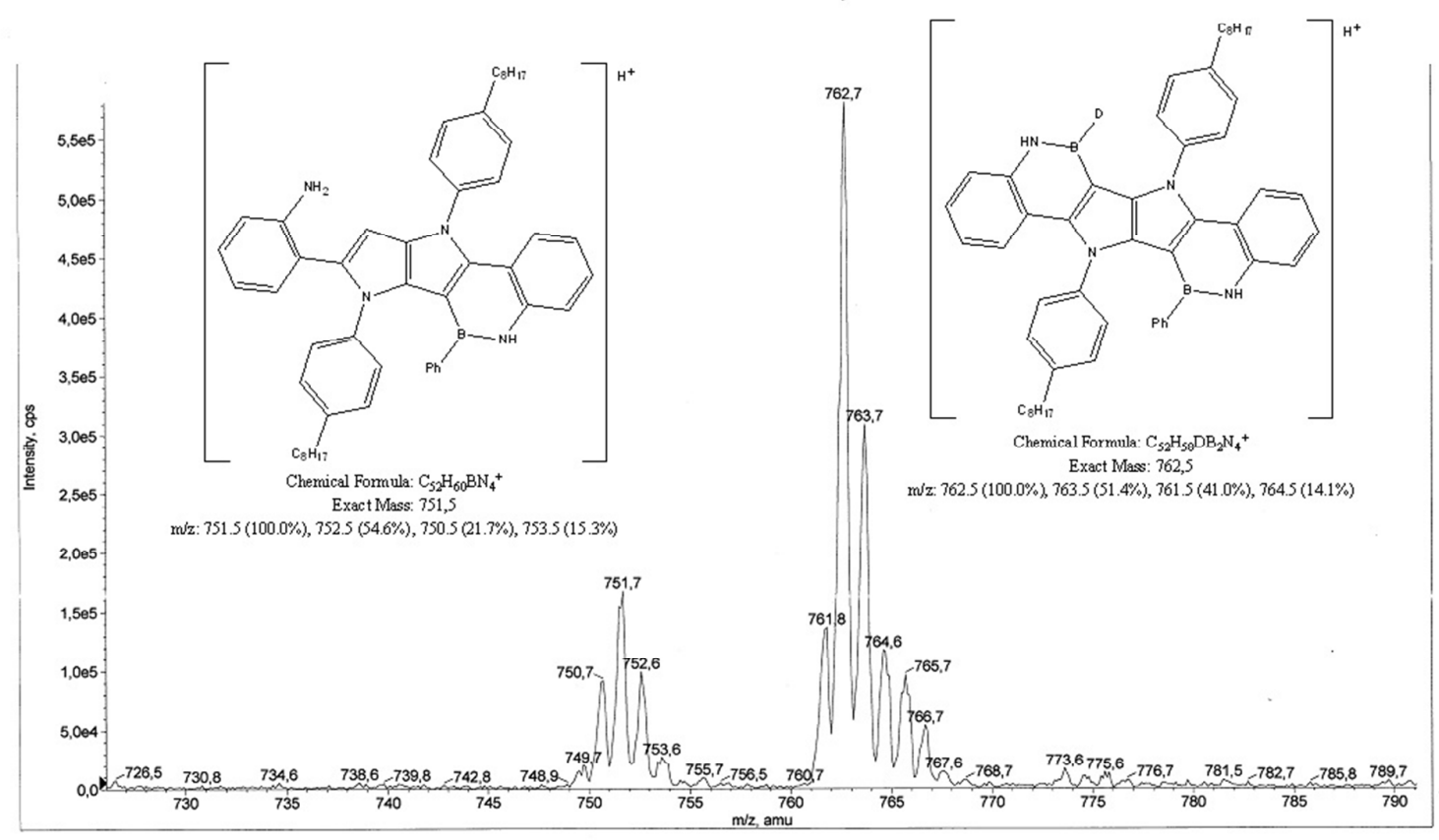

I

Figure S2. Enlargement of mass spectra (ESI) of compound 5 registered 5 days after it was dissolved in $\mathrm{CDCl}_{3}$. Only peaks originating from decomposition products were observed. 


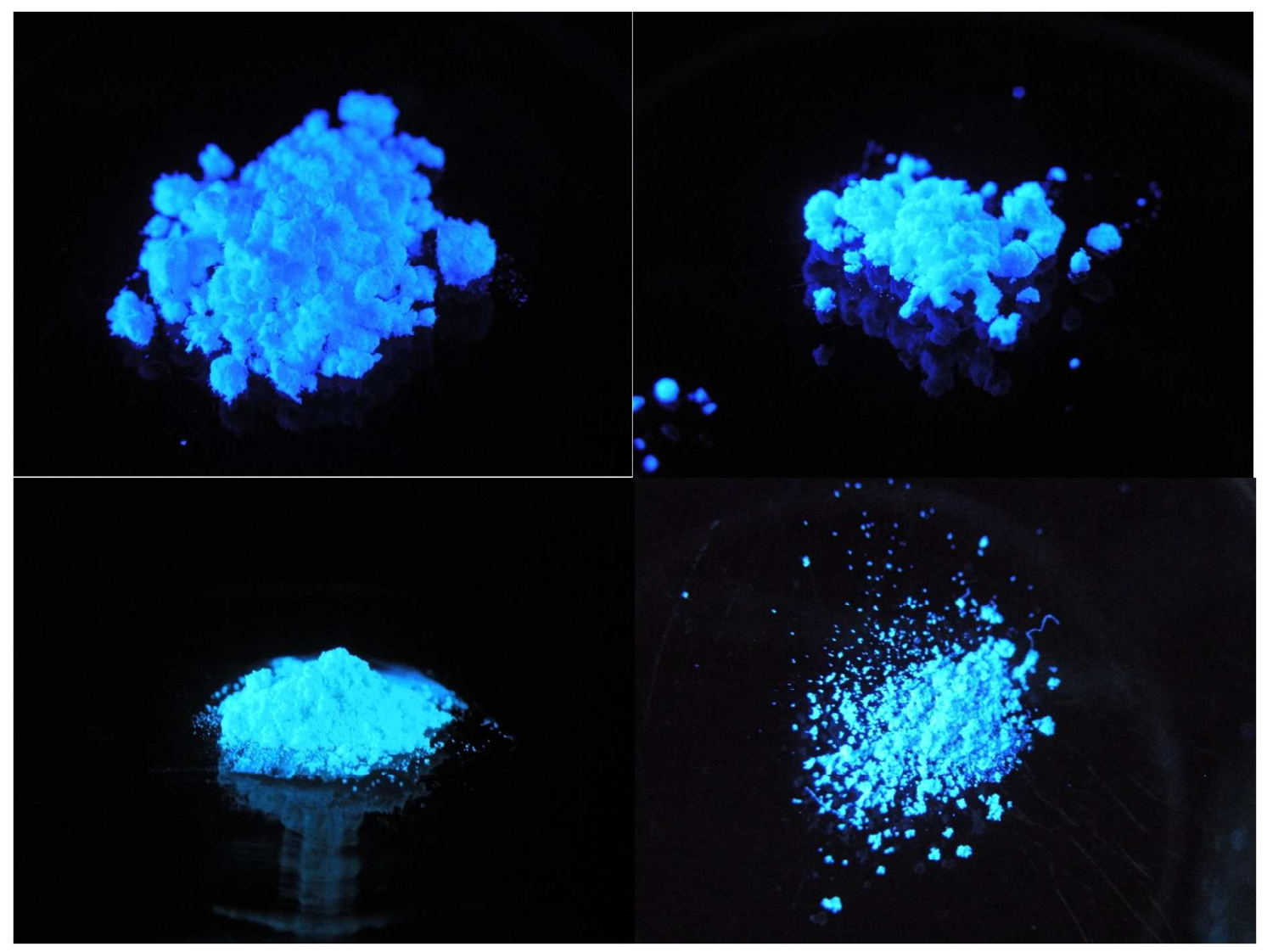

Figure S3. Photographic images of powdered samples of compounds 5 (top left), 6 (top right), 7 (bottom left) and $\mathbf{8}$ (bottom right) irradiated with ordinary laboratory UV-lamp (365nm). 